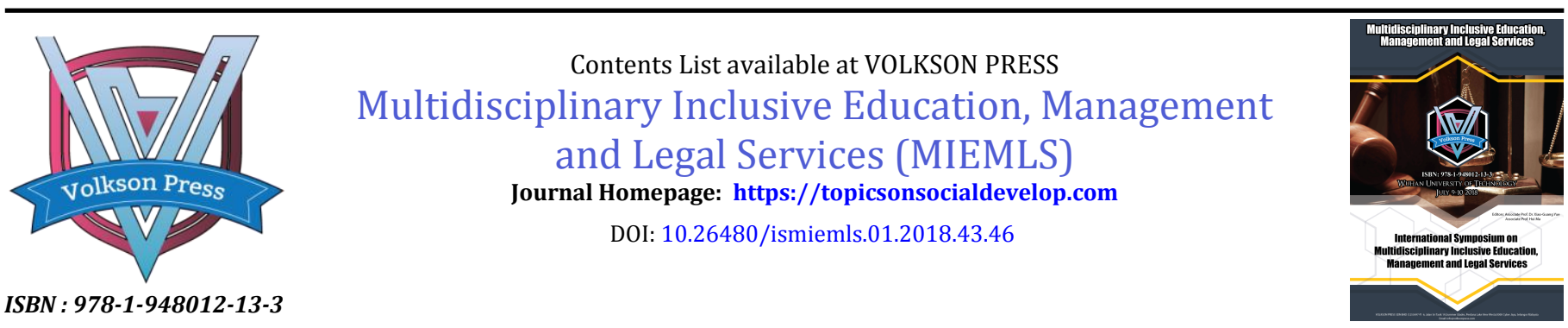

\title{
FOSTERING THE RED TOURISM BRAND FOR REVOLUTIONARY MEMORIAL MUSEUMS: A CASE STUDY OF THE LI XIAN'NIAN MUSEUM
}

\author{
Yansong Peng*, Guoxiang Guo \\ Modern and Contemporary Chinese History, Wuhan University of Technology, Wuhan, China \\ *Corresponding Author Email: Sunpys99@163.com
}

This is an open access article distributed under the Creative Commons Attribution License, which permits unrestricted use, distribution, and reproduction in any medium, provided the original work is properly cited.

\section{ARTICLE DETAILS}

Article History:

Received 26 June 2018 Accepted 2 July 2018

Available online 1 August 2018

\section{ABSTRACT}

With the successful convening of the 19th National Congress of the CPC, the statement "remain true to our original aspiration and keep our mission firmly in mind" has inspired numerous people's interest in reliving revolutionary memories. Hence, we must give top priority to fostering the "Red Tourism" brand for revolutionary memorial museums. Based on the actual circumstances of revolutionary memorial museums, this thesis is intended to improve their scenic architecture, open up a fascinating climate for tourism, create good displays and exhibitions, foster a charming "artistic atmosphere", enhance the quality of personnel, improve the functions of social services, place an emphasis on promotions, foster the tourism brand using unique characteristics, explore Red resources, and promote films and television productions. This thesis aims to explore ways of fostering the "Red Tourism" brand for revolutionary memorial museums from the perspective of marketing across sectors in order to spread Red culture and ensure that domestic Red Tourism can experience new momentum in this regard.

KEYWORDS

Revolutionary Museums, Red Tourism, Li Xian'nian Memorial Museum.

\section{INTRODUCTION}

Red Tourism has been regarded as a top issue for tourism in recent years, and as a result, tourism experts and scholars have conducted discussions and analyses on how to develop it. Through the creation and analysis of a literature review, it was found that the vast majority of research on Red Tourism focuses on resource exploration and preliminary development and research. The primary focus has been on the importance of developing and utilizing Red Tourism resources, as seen in A Study on the Integration and Development of Red Tourism Resources in Dabie Mountain by Mo Linli, as well as in Reflections on the Development of Red Resources at Jinggang Mountain by Xie Jiangling. Furthermore, research has been performed regarding the transmission of Red culture in terms of developing and utilizing Red Tourism resources, as seen through the Heritage of Red Culture in Terms of the Development of Red Tourism Resources by Huang Guangwen and A Study on Developing Red Culture and Red Tourism Resources in the Bohai Bay Zone by Cai Xiaoguang. An increasing number of articles has emerged on the development of the social functions of Red Tourism resources, such as A Study on the Development of Red Resources in Ganxi and Its Implications for Harmonious Culture by Luo Junfang and The Development of Red Resources and Education of the Core Socialist Value System by Li Kangping. Few articles currently exist on the development of Red cultural resources from the perspective of economic geography, for example, the FourDimensional Perspective of Red Cultural Resources Development by Liu Dingyu and Rao Zhihua. To date, few academic studies have investigated ways to foster the Red Tourism brands for revolutionary memorial museums, and research concerning revolutionary memorial museums has solely focused on how to spread Red culture and promote their social and educational functions, presenting a considerable opportunity for the composition of this thesis.

\section{SIGNIFICANCE OF RESEARCH}

The early 21st century is a time of considerable change in our world, and the stakes are high. However, there is a push underway around the world, and extraordinary energy is coming together to create new visions and possibilities where cultures flourish and we can make amends with our surroundings. Based on a study, culture remains the foundation for the world that humanity will occupy in the future, and the muses cannot be far away [1]. The protection and utilization of culture is a permanent issue. According to research, cultural resources management encompasses a broad range of issues related to the protection, preservation, and use of such sites [2]. Thus, we must foster our outstanding revolutionary culture according to these concepts.

Revolutionary museums and memorial museums regard revolutionary relics, such as former sites, relics, buildings, physical objects and literature, as physical carriers with memorial significance and historical value formed in the course of revolutions and wars and that are related to major historical events, revolutionary campaigns and essential characters under the leadership of the CPC of China. According to a scholar, these museums can also serve as physical witnesses to Chinese revolutionaries under the leadership of the CPC of China [3]. As is already known, revolutionary museums refer to topical museums that honor great historical events and historical figures in modern China; these sites nurture sentiments and purify hearts. Moreover, these museums also teach classes that promote the rejuvenation of national spirit and enhancement of the nation and promote experiences that integrate historical cultures, patriotic lessons and touristic sightseeing. The establishment of revolutionary memorial museums is targeted at better preserving, promoting and studying Red culture; hence, they bear a historical mission and contemporary responsibilities entrusted to them by the CPC and its people. The abundant and authentic materials available on Red culture demonstrate the optimal use of resources for providing a patriotic education to the Chinese people. Efforts should be made to employ precious Red culture resources to serve as a reminder of warning and education for the nation's descendants, which should be the inevitable mission and duty of each revolutionary memorial museum. The core connotation in this study is to educate descendants using the heroic deeds of revolutionary forebears, providing an essential base for the promotion of excellent revolutionary traditions and the spread of a patriotic education. Study showed these resources also serve as a crucial carrier for facilitating the transmission of Red culture [4]. As revolutionary memorial museums, a clear and systemic orientation for 
the correlation between the two purposes must be created that is conducive to facilitating operations in terms of the promotion of revolutionary memorial museums and the establishment of a solid foundation for the research and promotion of Red culture.

In the past, revolutionary memorial museums could be described as both "hustle and bustle" and "deserted". The underlying reasons for the deserted circumstances include subjective factors, such as lack of interest, secluded locations, outdated displays, and monotonous promotions. Exploitation and lack of interest repel people; however, opportunities and challenges can coexist. When the 19th National Congress of the CPC was successfully convened, the appeals "to hold a beginner's mind" and "to bear in mind the mission" presented excellent opportunities to revolutionary memorial museums through the events and characters included in their content. A brand-new opportunity for a project was presented that invoked support and attention from the community to rise to the occasion, seize opportunities for quickly changing the current conditions, and develop resources in the revolutionary memorial museums in a reasonable manner based upon rational protections in order to foster the "Red Tourism" brand.

Li Xian'nian Memorial Museum in Hong'an county, Hubei province attaches great importance to the outstanding contributions of Li Xian'nian to the Chinese revolution and China's development, and it attempts to display his legends featuring his ordinary, extraordinary, plain and legendary personal styles in terms of four units. These units include "craftsman to general", "secluded among the enemies to the edge of the Central Plains", "a leader in Hubei province for the management of national wealth" and "an outstanding leader for the CPC and the nation." As a traditional base for patriotic education and one of the key protected cultural relics for the province, this museum is committed to developing "Four Dabie Mountain", facilitating "Dual Rejuvenation and Prosperity", and conducting "ThreeProlonged Actions", which are a type of great leap forward for the historic moment when the Plan for the Development and Rejuvenation of the Former Revolutionary Sites in Dabie Mountain is unveiled.

\section{STATUS OF THE SUBJECT}

Situated in Kezi Mountain in honor of the Huangma Campaign in Hong'an county and Hubei, Hunan, Anhui and Jiangsu provinces, the Li Xian'nian Memorial Museum was authorized by the promotional department of the CPC of China in 1993, and construction on it began in his hometown in Hongan county, Hubei province on the fifth of April, 1994. This museum was officially opened to the outside world on the 21st of June, 1997. The museum covers an area of 5500 square meters, of which the constructed area amounts to 2227 square meters. The museum is built of brick and wood with white exterior walls and black steps. When visiting the museum, one finds a beautiful courtyard that is serious, elegant, ancient, cozy, serene and unique, thereby demonstrating an architectural feature with Oriental cultural connotations.

The Li Xian'nian Memorial Museum contains four display sections. However, due to improper maintenance, the museum's exhibits and buildings appear run-down, and its exhibits rely solely on propaganda lacking in good interpretations and design. The distribution of the displays is odd, the concepts presented fail to be fully formulated; few tourists find it personally appealing.

\section{RESULTS}

4.1 To improve the architecture in scenic spots so as to foster an enjoyable tourist environment

As Red Tourism witnesses this momentum and these comprehensive promotions, revolutionary memorial museums, as carriers for promoting national culture and rejuvenating national spirits, must prioritize the intensification of efforts in terms of environmentally protecting their infrastructure development, facilitating organic assimilation and overall developing natural, historical and cultural resources in accordance with the natural geographic environment. Thus, tourists can enjoy the beauty of architectural designs in scenic spots that are pleasant and comfortable environments for tourists. Currently, efforts have been made to revise relics zones and optimize environments so as to foster a cozy and beautiful environment for tourists. In this way, ancient architectural groups are characterized by plainness, elegance and an orderly distribution of tourist attractions that are blended into one, fully demonstrating the unique creations and regional characteristics of the cultural landscape through these revolutionary memorial museums.

Another crucial measure for tourism development in revolutionary memorial museums is to restore the revolutionary historical and cultural landscapes of former sites in order to intensify tourists' intense interest in these zones. Hence, the memorial museum is divided into a lobby, four exhibition rooms, a warehouse of historical relics and the restored display of President Li's office. The four presented exhibits include "craftsman to general", "secluded among the enemies to the edge of the Central Plains", "a leader in Hubei province for the management of national wealth" and "an outstanding leader for the CPC and the nation", which demonstrates his ordinary, extraordinary, plain and legendary personal styles. These exhibits introduce the glorious course of comrade Li Xian'nian's experiences from his beginning as a common craftsman and son of a farmer to him becoming a well-renowned general and the president of the country in the course of 66 years of revolutionary moments. This notable life is presented through physical objects, illustrations and pictures. In this way, increased interest can be sparked among tourists, thereby delivering the desired outcome among tourists. In addition, while maintaining better tourist environments for scenic locations, revolutionary memorial museums must cooperate with surrounding Red Tourist attractions for further development. For instance, the Dong Biwu Memorial Museum, which has a similar purpose, has assimilated into the general climate of "Red Tourism" in a joint endeavor to put marketing in place and foster a renowned "Red Tourism" brand. The goal is to be included in the concept roadmap for "Red Tourism" across the provinces and country and embark on a new phase of prosperous development for "Red Tourism" that transcends the boundaries between the provinces and the country as a whole.

\subsection{Layout for exhibitions to foster "a fascinating climate for art"}

Currently, revolutionary memorial museums in China are confronted with a number of issues, namely, odd and outdated content, stereotyped patterns for exhibitions and stereotyped and monotonous illustrations [5]. To embrace the upcoming surge of Red Tourism, revolutionary memorial museums should create new exhibitions, stimulate initiatives, adhere to the principle of "be adjacent to realities, lives and the masses", and ensure the integration of professionalism, academics, entertainment and appreciation, thereby enhancing national cohesiveness and a sense of pride for the vast majority of tourists.

The Revolutionary Memorial Hall should lay out its exhibitions well. However, the most significant change is to the display's content. Through improved display options, modern equipment, the distinctive features of the exhibition space, advanced technology and new art combinations, a perfect mix of display content and artistic expression can be created. Based on the photo exhibition, works of art, including paintings, photography, sculptures, landscapes and woodcuts, decorate the space. According to research, the overall exhibition boasts a stereoscopic sense of being in 3 dimensions [6]. In terms of creativity, a large number of symbolic shapes were employed, such as the broad scene rendering, many forms of space processing, the adoption of abstract plates, the composition of images and concrete graphics, and the assimilation of pictures, with various parts highlighting one to two historical points. In this way, the exhibition as a whole demonstrates the visual flow of rhythm, the rhythm of change and a sense of beauty. Not only is the new museum exhibition abundant in terms of content, but it is also elegant in terms of its form and strong visual impact. Also, we aim to comprehensively enhance appreciation for the scenic location by means of sound, light, electricity and other modern means, thereby attracting the attention of tourists as much as possible.

\subsection{Enhance personnel quality and improve social services functions}

We conclude by arguing that cities aspiring to become international destinations for cultural tourism should not neglect the quality of human capital and training [7]. Therefore, as a carrier for the spiritual and civilized development of socialism, as well as an essential promotional location for it, the quality and personalities of personnel represent the vitality of living and development for memorial museums [8]. In terms of tourism, the vast majority of tourists go to the scenic locations of revolutionary memorial museums to realize the dream of "experiencing Red enthusiasm once again and traveling around fascinating landscapes" by means of tours, entertainment and purchases. To this end, narrators undertake the dual tasks of a guide: spreading the cultural spirit in the 
scenic location and fostering the external impressions of the scenic location. Therefore, the primary factors contributing to the enhancement of service quality in revolutionary memorial museums are cultural quality and courteous impressions. Hence, memorial museums should hold to service principles, such as "being audience-oriented and taking their interests into account" and regarding their demands and social requirements as a starting point and ending point, thereby offering standardized, superior and personal service in daily life. We are obliged to improve external management and constantly improve staff quality, drawing upon the advanced managerial experience of other excellent museums and unveiling relevant regulations and duties for various posts in accordance with actual circumstances. In our daily work, we must improve awareness the staff's role to reach and satisfy the audience. Furthermore, we should vigorously encourage the staff to stand in the others' shoes and take the thoughts of the audience into account in order to explore and satisfy their unspoken demands. Though these services seem subtle, the audience can sense the warmth in their hearts. In addition, special attention should be paid to issues concerning unity in museums. Based on a study, museums should try to negotiate, exchange information, pay respect to elders, and support teenagers to foster a harmonious and cozy climate, setting a standard for modern service with the idea of "Treating museums as home and taking pride in their prosperity" for better social outcomes [9].

At the museum, an unstable organizational structure caused by frequent leadership turnover factored heavily into the creation of a noncollaborative workplace with ongoing personal conflicts. According to a scholar, the institutional and internal changes called for a more flexible management system than the traditional hierarchical structure [10]. Thus, we should avoid frequent changes in leadership at the Li Xian'nian Memorial Museum. By adopting the qualities of a learning organization that constantly evolves and grows, this museum can become a more effective and efficient organization with a stable management structure, sustainable and collective leadership, an effective communication system, and, therefore, be a positive, cohesive, and vision-driven workplace [11].

In addition, the Li Xian'nian Memorial Museum performs campus recruitment annually and trains students to be narrators. Through the rational and reasonable cultivation of the students, these narrators have experienced personal gains in various ways. The narrators have not only acquired a great deal of knowledge outside of their classes but have also enhanced their communicative competencies, as well as their selfconfidence. The narrators appear courteous, natural and fluent in their narration in a vivid and flexible manner, thereby demonstrating outstanding talent and receiving high praise from tourists.

\subsection{Place an emphasis on promotion in order to foster tourist brands with certain characteristics}

Scenic locations, such as those of revolutionary memorial museums, serve as tourist destinations for numerous tourists in the courses of their "Red Journeys." In order to improve the popularity of these scenic locations and attract more tourists, one feasible approach is to focus on packaged exhibitions to scenic spots, promote these visits in new ways and place an emphasis on fostering and fully displaying the tourist brands with an emphasis on the cultural connotations and historical and cultural charm of the locations. In terms of marketing strategies, museums must maximize their strengths.

For example, the Li Xian'nian Memorial Museum, as the largest existing museum promoting Li Xian'nian's legendary life, must deepen the spirits of the proletarian revolutionists marching out of Dabie Mountain represented by Li Xian'nian by focusing on great people like him in its marketing strategies. The core marketing strategy aims to reach people by analyzing the general public. Findings are applied to move people from simply admiring these great men to wanting to visit their memorial museums. Thus, tourists can show admiration for these great people and learn more about them.

The approaches to this promotion should be abundant, lively, vivid, and popular with the masses. Efforts must also be made to enrich the promotional content so as to intensify its effects: first, through tourist promotions, expositions and other means of building popularity; second, through newspapers, periodicals, television networks and other media publicity; third, through buses, pillars, flyovers and outdoor advertising; and four, through the production of commemorative films, scenic images,
DVDs, books and other similar means of promotion. Theatrical performances, roving exhibitions and other means of increasing popularity can also be adopted to attract people's attention, thereby enhancing visual effects and good outcomes. An emphasis should be made on the marketing object. As per tourist marketing theory, "absolutely not to promote the easy sell, absolutely not to promote sales, or to focus on promotion," for the middle of the "Swing Market" [12]. Efforts towards the potential of the social organizations and high-consumption forms of promotion must be made; this requires an in-depth analysis of the market, thus ensuring that a robust marketing scheme can be chosen. Meanwhile, incentive marketing can be adopted by treating travel agencies as a direct marketing body and indirect consumers in order to enhance the success of the memorial museums [13].

\subsection{Explore Red resources and integrate film and TV transmission in order to strive for promotions across sectors}

Revolutionary memorial museums boast an important history, conceal earth-shattering stories, and witness the vicissitudes of times. With time passing by, social communities will come to hold nostalgic beliefs regarding history. Revolutionary memorial museums should be adept at seizing opportunities in various forms and by various means, particularly through the adoption of films and television for the dissemination of this important history and to maximize the social and economic benefits of doing so. For example, the First Normal University in Hunan Province has made a national sensation of the Young Mao Zedong Memorial Museum through the "As a Youth" TV series, which had ratings of $8.92 \%$ for its premiere, a notable achievement for a Red revolutionary TV series in terms of ratings [14].

Currently, against the backdrop of the dramatic social changes, the expansion of desires and conflicts around diverse values, young teenagers enjoy happiness brought about by abundant physical prosperity while being confronted with insufficient faith and pain induced by poor spirits. In this context, the value of the characters of Red culture tends to be more far-reaching, especially when vulgar talent shows, and dramatic court dramas prevail on the screen. Red memorial venues should present the appeal and respect of community as part of mainstream values through films and television programs, thus achieving the theme of culture as well as mass culture of the performance, which is a universal reference for revolutionary memorial museums.

Efforts should be exerted to integrate the promotion of Red culture and new media online for the revolutionary memorial museums, thereby demonstrating the characteristics of the era in the course of the development of revolutionary memorial museums. With the advent of the Internet plus era, people have greater demands for culture, and the types of demands being made have undergone remarkable changes. According to research, red culture must be integrated with the developments of the current times such that it can survive, develop, be assured of its ongoing vitality for Red culture. Thus, it is highly important that revolutionary memorial museums not ignore this new online platform. Revolutionary memorial museums can also take advantage of various means of sharing high-tech information in order to promote Red culture. Meanwhile, virtual realistic technologies can be employed to display precious items in revolutionary memorial museums in order to ensure more vivid and visual images and descriptions for various relics, enabling the general public visiting the museums to gain more authentic and 3-dimensional effects, intensifying their recognition and knowledge of revolutionary history. In the meantime, online platforms are capable of offering real-time content, offering engagement and interaction for the vast majority of tourists nowadays. The staff at revolutionary memorial museums can deliver better performances in terms of interaction and exchanges with tourists, thereby ensuring a dual and diversified form of communication. In this way, real-time interactions can not only provide a better platform for learning but also extend access to education regarding Red culture to tourists, thus stimulating sentimental demands for tourists to learn about revolutionary spirits.

\section{CONCLUSIONS}

It is an inevitable responsibility and mission for each revolutionary memorial museum to promote Red culture. Against the backdrop of globalization, revolutionary memorial museums should enhance the cultural quality of staff and conduct research on the means and strategies of Red culture transmission. The museums should also proactively 
innovate their content and its forms of transmission. Furthermore, outcomes can be registered based upon the principle of respecting the value of Red culture itself in order to ensure better promotions and protection of Red culture and to strive for its sound and sustainable development. In the final analysis, as long as the revolutionary memorial museums seize these golden opportunities and make efforts to conform to the realistic conditions in terms of their environments, displays, services and promotions, they can foster the Red Tourism brand, appeal to a larger audience, prevent yielding to difficulties in the market economy and march forward courageously. These museums can be regarded as sacred sites for the promotion of patriotism and educations in revolutionary traditions.

\section{ACKNOWLEDGEMENTS}

This paper is supported by the Excellent Dissertation Cultivation Funds of Wuhan University of Technology (Project number: 129-13053).

\section{REFERENCES}

[1] Worts, D. 2016. Fostering a Culture of Flourishing. Curator, The Museum Journal, 59 (3).

[2] Ahmed M. Abd El-Rahman Shehata, Mohsen Mohamed Ibrahim Mostafa. 2017. Open Museums as a Tool for Culture Sustainability. Procedia Environmental Sciences, 37.

[3] Dang, Z.J., Wang, W. 2014. The Development of Revolutionary Memorial Museums and Socialist Core Values System - A Case Study on Yan'an Revolutionary Memorial Museums. Cultural Research, (7), 169-170.

[4] He, L.Q. 2015. A Preliminary Study on the Revolutionary Memorial Museums and Transmission of Red Culture. Cultural and Historical Aspect, (32), 102-103.
[5] Chen, S.G. 2012. Interpretation of History and Promotion of the Mainstream - A Study on the Role of Revolutionary Memorial Museums in Red Tourism. Hei Longjiang Historical Magazine, (15), 79-81.

[6] Yang, H., Liao, H.P., Li, S.Q. 2011. A Study on the Development of Red Tourist Products for Teenagers - A Case Study of Hunan Province. Journal of Jiangxi Science and Technology Normal University, (2), 22-23.

[7] Antonio, P.R., van der Borg, J. 2002. Planning Considerations for Cultural Tourism - A case study of four European cities. Tourism Management, 23 (6).

[8] Wu, Y.P., Shi, P.X., Chen, Z.Y. 2016. Marketing Innovation of Red Tourist Destinations under the Discourse of the Chinese Dream. Guizhou Social Science, (1), 33-34.

[9] Liu, H.M., Zhang, H.Y. 2013. The Guide Narration and Promotion of Red Culture in Red Tourism. Journal of Jinggang Mountain Social Science, (4), 54-55.

[10] Jung, Y.H. 2016. Micro Examination of Museum Workplace Culture - How Institutional Changes Influence the Culture of a Realworld Art Museum. Museum Management and Curatorship, 31(2).

[11] Wu, B.H. 2006. Development Management and Promotion for Red Tourism. China Architectural and Building Press, (8).

[12] Yang, Y. 2016. Enhancement of Red Culture Soft Strength and Facilitation of Sustainable Development of Red Tourism - A Case Study of Qin Huang Island. An Era of Wisdom and Prosperity, (S1), 44-46.

[13] Zhong, C. 2007. Eulogy on the Glorious Aspects of man - Analysis on the Character Cultivation in TV series entitled A Dream of Youth. Hu'nan Daily Newspaper.

[14] Chen, J. 2016. Analysis on Red Culture against the Backdrop of Internet. Boundary Economics and Culture, (1), 29-30. 